\title{
The synergistic anticancer traits of graphene oxide plus doxorubicin against BT474 and MCF7 breast cancer stem cells in vitro
}

Mahsa Ebrahimi

Azad University: Islamic Azad University

maryam teimouri ( $\nabla$ teimourimaryam93@gmail.com )

Islamic Azad University https://orcid.org/0000-0002-6609-5415

Mehdi Pooladi

Azad University: Islamic Azad University

\section{Research Article}

Keywords: Graphene oxide, Breast cancer, Apoptosis

Posted Date: April 22nd, 2021

DOI: https://doi.org/10.21203/rs.3.rs-361091/v1

License: (c) (i) This work is licensed under a Creative Commons Attribution 4.0 International License.

Read Full License

Version of Record: A version of this preprint was published at Applied Biochemistry and Biotechnology on July 29th, 2021. See the published version at https://doi.org/10.1007/s12010-021-03623-8. 


\section{Abstract}

Breast cancer is among leading causes of death due to cancers around the globe. Current therapeutic approaches towards healing of breast cancer have been associated with poor outcomes. Graphene and its derivatives have a two-dimensional flat structure, which is characterized by the ability to carry drugs and modify the surface, low cytotoxicity and high biocompatibility. This study was performed on MCF7 and BT474 human breast cancer cells. Different concentrations of doxorubicin (DOX), graphene oxide (GO) and graphene oxide plus doxorubicin (GO-DOX) were subjected to both cell lines at specified intervals. At the end of the treatments, MTT test was applied to determine the viability of cells and then flow cytometry, colony formation and spheroid tests were implemented for both cell lines treated with DOX, GO and GO-DOX components. We used DLS and TEM to confirm the GO properties. According to the MTT test results, $1 \mu \mathrm{L}$ of DOX at $10 \mathrm{mg} / \mathrm{mL}$ (equivalent to $0.1 \mathrm{mg} / \mathrm{mL}$ ) caused $50 \%$ survival of MCF7 cells at 24 hours. In both cell lines, an increase in apoptosis occurred after incubation with GO and DOX. Although, a rate of mortality of MCF-7 cells was due to necrosis, the BT474 cells death was merely through the apoptosis. Furthermore, the results of colony formation test outlined an enhancing inhibitory effect in the presence of GO-DOX as a comparison to the control. Additionally, spheroids formed following treatment with GO-DOX exhibited a significant decrease compared to their control group; with an increase in the number of spheroids in BT474 cells compared to those in the MCF-7. The decreasing effect of compounds against the migration and cell invasion potential was also observed, being higher in MCF7 than BT474 cells. The effects of cytotoxic GO were observed at higher concentrations.

\section{Introduction}

Cancer is a group of diseases due to the uncontrolled division of cells in the body. Cancer is a substantial increasing worldwide problem occurred in numerous forms causing the death of more than a third of the world's population. The disease is growing rapidly in developed countries because of alterations in population and risk factors resulted from negative impact of environmental factors increased in a variety of cancers (1-3). Breast cancer is the predominant cancer among various age groups of women, accounting for $25 \%$ of all cancers, there is currently no definitive and permanent treatment for this complex disease, though has occurred for a long time. High death rate and lasting time of diagnosis, high costs and side effects of chemotherapy are additional concerns. Therefore, seeking effective therapeutic approaches is promising in promoting the health of the global community $(4,5)$.

Breast cancer include a diverse population of cancer cells in terms of phenotype, for which common treatments are suggested, including surgery, radiation therapy, chemotherapy, hormone therapy, and biological therapies (6). These approaches vary depending on the progression of the cancer, type, and physical condition. Cancer treatment is either topical or pervasive. Nowadays, targeted treatment is fulfilled with nano drugs. Nanotechnology has the potential to bypass several forms of conventional therapeutic formulations. In fact, significant steps have been taken to use engineered nanomaterials to treat cancer with high specificity, sensitivity and efficiency. Nanomaterials made with specific ligands can target cancer cells in a predictable way and deliver encapsulated drugs effectively and purposefully. In 
addition, nanomaterials can also be designed to increase drug loading, improve body half-life, and selectively distribute by changing their composition, size, morphology, and surface chemistry $(7,8)$.

Graphene oxide is a novel, monolithic structure of the well-known material graphite oxide. Graphite is the most common crystalline form the quaternary carbon atom. Indeed, it is a three-dimensional structure of carbon allotropes that has a layered structure in which quaternary carbon atoms are connected to three other carbon atoms through three covalent bonds and form a hexagonal lattice structure. Graphene is a layer of carbon atoms arranged with SP2 hybrid in a honeycomb shape, forming a two-dimensional crystal lattice, firstly synthesized in $2004(9,10)$. Due to the unique structure and geometry of this material, graphene can be expected to have significant physical and chemical properties, including the ability to modify the surface. Biochemical applications of graphene-based materials such as graphene oxide, including rapid drug delivery, have been used in recent years extensively and impressively due to the unique properties of two-dimensional, flat structure, large chemical surface area, high mechanical and chemical stability, low cytotoxicity and biocompatibility. These properties have led to a promising approach to the design of drug delivery systems and the introduction of a new range of graphene-based therapies (11-13).

The shape of graphene plays a substantial role. The unique two-dimensional shape and flatness of graphene and graphene oxide and the absence of this structure in the morphology of the biological system of the human body is another advantage of using this nanocarrier in drug delivery. Graphene and graphene oxide are also important in terms of the strength of the nanocarrier and increase the ability to penetrate into the cell, and due to the efficient thickness of graphene and its derivatives, being promising in the cell biocompatibility. In addition, the withstanding structure of these materials maintains their integrity during drug carriage $(14,15)$.

The aim of this study was to investigate the effect of graphene oxide on MCF7 and BT474 human breast cancer stem cells. For this purpose, different concentrations of doxorubicin (DOX), graphene oxide (GO) and graphene oxide and doxorubicin (GO-DOX) were subjected to two cell lines at specific time intervals. The physicochemical characterization of GO was confirmed by DLS and TEM. At the end of drug treatments, MTT assay was used to determine cell viability. Flow cytometry test was also conducted to determine the extent of apoptosis, multiplication to evaluate the ability of cells to differentiate into other cancer cells, spheroid to evaluate the ability to form spheres in non-stick medium, for both cell lines treated with DOX, GO and GO-DOX.

\section{Methods}

- Synthesis of graphene oxide

To prepare GO, graphite powder was used as per the Hammers method (16). Firstly, $2 \mathrm{~g}$ of graphite (500 mesh) and $80 \mathrm{~mL}$ of concentrated sulfuric acid were poured and stirred. Gradually $2 \mathrm{~g}$ of sodium nitrate and $12 \mathrm{~g}$ of potassium permanganate were added to give a sludge-green mixture. Then $46 \mathrm{ml}$ of 
deionized water was added to the reaction vessel and stirred for 30 minutes. Next, deionized water and 16 $\mathrm{mL}$ of $30 \%$ hydrogen peroxide was added to the reaction mixture. The obtained precipitate was placed in an ultrasonic bath for 30 minutes and the produced solution was washed and filtered with $10 \%$ volumetric HCL solution in water 3 to 4 times. The obtained brown solid precipitate was separated by centrifugation and dried for 24 hours in an oven at $50^{\circ} \mathrm{C}$.

Transmission electron microscopy (TEM) was used to characterize the prepared GO and DLS test was used to determine the particle size and dispersion of the drug. Then all the treated cells were exposed to GO for 24 hours, then GO was removed and DOX was added for 24 hours (GO-DOX group).

- DLS

The synthesis of GO particles was performed by Zeta Sizer (Maldon UK ZS series model) at room temperature and 90 degree angle.

- TEM

In order to evaluate ad confirm the morphology and the size of GO, a drop of the particle suspension sample was placed on a carbon film grade and after drying at laboratory temperature using TEM KV 100 model (Leo 906 Zeiss, Germany), was photographed with an accelerator voltage of Kv120.

- Cell Culture

In this study, two breast cancer stem cells (MCF7 and BT474) were used. The cells were obtained from the Iranian Genetic Stores Center in frozen form and cultured into the DMEM (Dulbecco's Modified Eagle Medium) medium with $10 \%$ fetal bovine serum (FBS) supplement. Cells acidic metabolites produced during their proliferation causes the culture medium to gradually change color from purple to yellow. For this reason, the cell culture medium was substituted every 24 to 48 hours. When cell density reached $80 \%$, cell passage was performed by adding trypsin.

To freeze the cells, the flask supernatant materials was drained, and then washed with $1 \mathrm{X}$ phosphate buffered saline (PBS). Cell isolation was performed physically at $37^{\circ} \mathrm{C}$. The contents of the flask were poured into a flask containing the culture medium until trypsin function cease. The Falcon containing the suspension was centrifuged at $1500 \mathrm{~g}$ for 6 minutes, then frozen in the microtube. Freezing medium contained $50 \%$ DMEM, 40\% FBS, and 10\% dimethyl sulfoxide (DMSO). 


\begin{tabular}{|c|c|c|c|c|}
\hline Eff & Diam. (nm) & Half width (nm) & Polydispersity & Baseline Index \\
\hline $\begin{array}{l}1 \\
2 \\
3 \\
4 \\
5\end{array}$ & $\begin{array}{r}560.0 \\
1494.1 \\
915.8 \\
1672.8 \\
1871.1\end{array}$ & $\begin{array}{l}239.7 \\
105.6 \\
374.1 \\
118.3 \\
132.3\end{array}$ & $\begin{array}{l}0.183 \\
0.005 \\
0.167 \\
0.005 \\
0.005\end{array}$ & $\begin{array}{l}0.0 / 90.54 \% \\
0.0 / 100.00 \% \\
2.5 / 100.00 \% \\
0.2 / 95.52 \% \\
5.5 / 95.52 \%\end{array}$ \\
\hline $\begin{array}{l}\text { Mean } \\
\text { Std. Error } \\
\text { Combined }\end{array}$ & $\begin{array}{r}1302.8 \\
244.8 \\
1017.3\end{array}$ & $\begin{array}{r}194.0 \\
50.9 \\
254.1\end{array}$ & $\begin{array}{l}0.073 \\
0.042 \\
0.062\end{array}$ & $\begin{array}{l}1.7 / 96.31 \% \\
1.1 / 1.76 \\
6.8 / 96.32 \%\end{array}$ \\
\hline
\end{tabular}

Table 1. Results of DLS analysis which represented particle diameter and GO dispersion

- MTT test

The 3- (4, 5-dimethylthiazol-2-yl) -2,5-diphynyltetrazolium bromide (MTT) test was based on subject of the cells to various concentrations of the drug (GO-DOX) and measuring the rate of cell death. For this purpose, the yellow active substance tetrazolium and the formation of insoluble purple crystals of formazan were used in the MTT method. In this method, 24 hours after culturing the cells with the desired concentration, the supernatant culture medium was substituted and the cells were cultured for 3 hours with culture medium containing tetrazolium dye. Then, the medium was combined using $100 \mu \mathrm{L}$ of dimethyl sulfoxide and the amount and intensity of adsorption were read using an ELISA reader device at a wavelength of $570 \mathrm{~nm}$.

Evaluation of apoptosis by flow cytometry

Flow cytometry was used to evaluate the extent of apoptosis in MCF7 and BT474 cancer cell lines as a result of incubation with GO and DOX (GO-DOX) compared to the control and DOX groups. After the relevant treatments, the cells were trypsinized, then centrifuged at $1200 \mathrm{rpm}$, followed by $5 \mathrm{~mL}$ of phosphate buffer. After re-centrifugation, $1 \mathrm{ml}$ of kit buffer was added and after intense pipetting, $5 \mathrm{ml}$ of Annexin $\mathrm{V}$ was added and incubated for 4 minutes in dark conditions. Finally, $4 \mu \mathrm{l}$ of propidium iodide solution was added and analyzed by flow cytometry.

- invasion and cell migration rate

Firstly, $8 \mu \mathrm{L}$ filters were covered with a matrix layer and 25,000 cells per well were transferred to the filter with serum-free culture medium. The cells inside the filter were then removed using a wet swab, and then the invading cells passed through the matrigel and filter were counted. To perform the test, the cell culture medium in which the cells had reached a obtained degree of growth were replaced with the new culture medium having $0.2 \%$ BSA and placed in the incubator to induce starvation in the cells for an overnight. The cells were then washed with PBS solution and separated from the flask surface by Tripsin / EDTA enzyme. the enzymatic activity was inhibited by adding the culture medium containing $5 \%$ FBS with twice 
amount of the enzyme volume and then cell sediment was prepared using centrifugation at $750 \mathrm{~g}$ for 5 minutes.

the cell precipitate was dissolved into $1 \mathrm{~mL}$ of culture medium and $50 \mu \mathrm{L}$ was taken to count using $0.04 \%$ trypan blue. We then adjusted the cell density to 125,000 viable cells per milliliter of culture medium and added $600 \mu \mathrm{L}$ of new culture medium to each well. The coated filters were then incubated with $300 \mu \mathrm{L}$ of serum-free culture medium at room temperature for one hour to perform the hydration. Then $200 \mu \mathrm{l}$ of cell suspension in culture medium was added to each filter (about 25,000 cells per well), and incubated the cells in $37^{\circ} \mathrm{C}$ and $5 \% \mathrm{CO} 2$ incubator for 10 hours. Finally, to calculate cell invasion and migration, the average of them was counted under a microscope.

- Colony formation ability test (sphericity test)

Firstly, 100,000 BT474 and MCF7 cells wre cultured into a T25 flask and then $5 \mathrm{ml}$ of serum-free culture medium containing growth factors BFGF $20 \mathrm{ng} / \mathrm{ml}$ and EGF $20 \mathrm{ng} / \mathrm{ml}$ were added into th flask. In the next step, the culture dishes were transferred to an incubator with $37.5^{\circ} \mathrm{C}$ and $5 \% \mathrm{CO} 2$ without shaking for 48 hours. In order to change the environment of the spheres, the culture medium containing the spheres was pipetted and gently transferred to $15 \mathrm{ml}$ tubes, and the spheres were slowly settled. the cells were centrifuged at $1000 \mathrm{rpm}$ to precipitate, then the supernatant was removed and new medium was gently added from the side of the tube not to rupture the spheres. Then we transferred the spheres to our flask. Every three days, the culture medium was substituted and the new medium containing growth factors was added.

In order to calculate the percentage of cell line spherogenesis, the medium containing spheres was transferred from the culture dish to a sterile tube and pipetting was conducted gently so that the cell aggregates be disintegrated and a uniform solution achieved remaining the spheres. Then, using a suitable micropipette, $100 \mu$ l of the suspension containing the spheres was removed and placed in a nonstick container. We then counted the spheres using a stereo microscope with 40x magnification.

- Graphene oxide properties

GO was prepared from graphite powder following Hammers method. The results revealed that the synthesized solution contained proper conditions in terms of physicochemical properties. According to the TEM image, GO multilayer with a size of $2 \mu \mathrm{m}$ was formed (Figure 1).

DLS results outlined that the average particle diameter was $1302 \mathrm{~nm}$, and polydispersity of 0.07 , represented the efficient particle dispersion (due to $<0.1$ ), indicating the single dispersion (table 1 ). Accordingly, GO particles were dispersed properly in the solution without any accumulation.

- MTT test results

The effect of GO on MCF7 and BT474 cancer cell lines revealed that IC50 for GO was $40 \mu \mathrm{g} / \mathrm{mL}$ which was considered for further tests. MTT assay was implemented to determine cell survival and IC50 
concentration of GO-DOX on MCF7 and BT474 cells in 24 hours applying various concentrations of drug against cells.

Figure 2A depicts the MTT test at concentrations of $0,1,2.5,5$, and $10 \mu \mathrm{g} / \mathrm{mL}$ GO-DOX after 24 hours on MCF7 cells. Additionally, as represented in figure 2B, by increasing the concentration of GO-DOX, the survival rate of BT474 and MCF7 cancer cell lines was significantly decreased compared to the control group. Figure $2 \mathrm{C}$ demonstrates a diagram of both cells where MCF7 cancer line cells are more affected by GO-DOX in a concentration-dependent behavior compared to BT474 cells. Interestingly, there was a difference between the survival rates for both, which was significant for concentrations of $1(p=0.003)$, $2.5(p=0.003), 5(p=0.00009)$, and $10 \mu \mathrm{g} / \mathrm{mL}(\mathrm{p}=0.0001)$, respectively.

- Determination of LC50 concentration

The concentration at which $50 \%$ of cell death occurs is known as $50 \%$ lethal concentration (LC50). The stock concentration of doxorubicin was $10 \mathrm{mg} / \mathrm{mL}$, which according to the results of the MTT test within 24 hours for MCF7 was $\sim 1 \mu \mathrm{L}$ of stock and $10 \mathrm{mg} / \mathrm{mL}$ GO-DOX caused $50 \%$ survival which was equivalent to $0.1 \mathrm{mg} / \mathrm{mL}$. However, for the BT474 LC50 cell line, it was not reported for GO-DOX because of lower than $50 \%$ death rate at high concentrations. It should be noted that a concentration of $0.1 \mathrm{mg} /$ $\mathrm{mL}$ was used in subsequent experiments.

- Aptosis rate using flow cytometry

Concentration of GO-DOX IC50 was used for flow cytometry test and determination of the amount of apoptosis. Figure 4A shows the results obtained from flow cytometry and the results of Annexin and PI (Propidium iodide) test showed a significant increase in the apoptosis in MCF7 cancer cell line compared to the control group. The same is true for BT474 cells (Figure 4B). This suggests that GO-DOX increased apoptosis in the BT474 cancer cell line compared to the control group. In both cell lines, the percentage of apoptotic cells was significantly increased compared to the control $(P<0.001)$.

According to the results of the Figure 5 for the both cell lines, there was a significant increase in apoptosis and necrosis following incubation with graphene and doxorubicin, which resulted in a mortality rate in MCF-7 cells. However, in BT474 cells the mortality was mainly related to the apoptosis. The paired t-test analysis between GO-DOX group and the other two groups, namely DOX and control for both cell lines, showed a significant higher rate of apoptosis in the GO-DOX group compared to the other two groups. In MCF-7 cells, the rate of necrosis was also significantly higher compared to the other two groups.

- The ability of colony formation

Colony formation potential in MCF7 cell group treated with DOX, GO, GO-DOX was evaluated and compared with control. Morphologically, the size of colonies from MCF7 cell group treated with control was completely different. According to figure 6 , the colony forms in the treated groups were different from those of the control. For instance, the number of single cells in the treated groups was substantially 
increased, and this disclosed that the cells formed colonies during the 7 days. The treatment prevented the formation of colonies, while in control cells they were able to form colonies with the well-known forms of holocolon, paracolon, and morocolon. Additionally, with the presence of GO-DOX, the inhibitory effect on the cells was significantly higher in comparison with the control cells $(p<0.05)$.

- Spheroid test

In fact, in the spheroid test, the ability of spheres to form in a non-sticky environment was examined. In this test, the number of spheres produced after formation and treatment with GO and GO-DOX was evaluated. Figure 7 depicts two-cell spheroids under the influence of GO and GO-DOX compared to the control group. The t-test analysis on the number of spheroids formed in the control of two cell lines also outlined a significant difference between spheroids with an increase in the number of spheroids in BT-474 cells compared to the inhibited MCF-7.

- Cell invasion and migration

As shown in the figures 8 and 9 , the transvel plate containing the cell with or without matrigel have been represented. In the figure 8 , the rate of cell migration and invasion was determined by counting the remaining cells after staining on the transvel plate without the presence and presence of matrigel, respectively. MCF7 cells had a higher percentage of invasion than BT474 cells due to the lack of their presence in the cell count on transvel without matrigel, while they had a high percentage of presence in transval containing matrigel. In case of BT474 cells in both conditions, the percentage of cells was similar to each other, so they showed a low percentage of invasion. The number of MCF7 cells count was significantly different in DOX, GO, GO-DOX groups with and without matrigel, while in BT474 cells only in DOX group there was a significant difference between the both conditions.

\section{Discussion}

The apoptosis is a common cascade developed due to the toxicity induced by many anticancer drugs. Here, we surveyed whether the cytotoxic effects of GO against cancer cell line were due to the apoptosis. The results outlined that GO increased the apoptosis in the breast cancer cell lines. Activation of the Caspase cascade at the onset of apoptosis has been shown to be important in many biological systems. A member of this family, caspase-3 has been identified as a key mediator of apoptosis (17).

Tang et al., prepared the GO-DOX compound for the targeted delivery of chemotherapy drug, using the release property of $\mathrm{pH}$-sensitive drug $\mathrm{GO}$. The drug loading test showed that the best preparation conditions were GO-DOX with a reaction of $0.1 \mathrm{mg} \mathrm{GO}$ with $2 \mathrm{mg} \mathrm{DOX}$. The combination of GO-DOX showed five times more efficiency than DOX for release of $\mathrm{pH}$-responsive drug. They further report that when intracellular uptake of $\mathrm{GO}$ is excessively blocked, leading to increased cytotoxicity in vitro, the IC50 inhibitor concentration of GO-DOX is $7.3 \mathrm{mg} / \mathrm{mL}$ compared to DOX of $5.32 \mathrm{mg}$. / mL. Flow cytometric analysis showed a higher rate of apoptosis for GO-DOX-treated cells compared to DOX. As a result, they stated that the high loading capacity of DOX on GO, in addition to the $\mathrm{pH}$-dependent drug composition 
behavior, could cause drug release after endocytosis and maintain the high concentration in the MCF-7 cells in terms of cytotoxicity $(18,19)$. Fiorillo et al., exhibited that $\mathrm{GO}$ is able to specifically inhibit the growth and proliferation of cancer stem cells. They proved that $\mathrm{GO}$ can inhibit cancer-sphere in a variety of cancers such as breast, ovarian, prostate, lung, pancreas and glioblastoma (20). In the same study, Yoon et al, showed that the GO is not toxic to natural stem cells. To illustrate the importance of the issue $(21,22)$, we refer to the findings of research by Yang et al., Ku Sh et al., And Alibolandi et al. Mechanisms of graphene toxicity enhancement may include: Physical degradation and production of a variety of reactive oxygen species $(23-25)$.

Graphene enters cells through physiological barriers or cellular structures and using various methods of exposure, and ultimately leads to toxic effects on different pathways, distribution and excretion of different tissues, even the pattern of different cell uptake that determines the degree of toxicity. Graphene enters the cell through several pathways, such as endocytosis and can lead to the production of reactive oxygen species, increased lactate dehydrogenase, and calcium ion and malondialdehyde release. In addition, graphene can cause cell damage such as cell membrane damage, inflammation, DNA damage, and mitochondrial disorders. The result of this function is the activation of apoptosis or irreversible cell necrosis $(26,27)$. Yuan et al., reported in 2017 that high concentrations of graphene were toxic to liver cancer cells (28).

Studies have revealed that indirect contact of mammalian cells with graphene causes cytotoxic reactions, such as the production of ROS and oxidative stress, followed by the release of cytokines and inflammation. The degree of toxicity of graphene carbon depends on factors such as: physicochemical details including size, morphology, surface charge, purity and accumulation. Notably, the MTT test may not be able to accurately determine the cytotoxicity of graphene because of relatively low specificity (29, 30).

Several studies have shown conflicting results regarding the cytotoxicity and safety of graphene compound. For example, Chen et al., in 2013 reported that bacterial-reduced graphene oxide and graphene oxide increased MCF-7 cell line toxicity. They have disclosed that the toxicity of graphene oxide is dose dependent and has a high toxicity at a dose of $60 \mathrm{mg}$ (31). Conversely, Chang et al, reported that GO was not significantly toxic to the A542 and Hela cell lines (32). Another study evaluating the toxicity of oxidized monolayer carbon nanotubes and GO on HepG2 cells showed that monolayer carbon nanotubes increased the level of ROS, stimulated the cell and increased the rate of apoptotic cells in vitro significantly. However, only moderate changes in protein levels were observed for GO-treated cells, and further functional tests confirmed that $\mathrm{GO}$ was less toxic than oxidized monolayer carbon nanotubes. These findings suggest that $\mathrm{GO}$ is environmentally more biocompatible $(33,34)$. Another study by Vallabani et al, found that graphene had lower cytotoxicity to human normal lung cells (35).

One of the most important issues for the biomedical applications of graphene is its short and long term toxicity. Although there are some reports on the effects of graphene cytotoxicity in vitro, there is still no indepth understanding of the mechanisms involved in graphene cytotoxicity $(36,37)$. 


\section{Conclusion}

The results revealed that in both cell lines an increase in the apoptosis was occurred following incubation with GO plus DOX (GO-DOX), with an alternative induction of necrosis in MCF-7 cells. However, in BT474 cells cell death was mainly related to the apoptosis. Moreover, comparison of DOX, GO and GO-DOX groups with controls exhibited that GO-DOX conferred a significantly higher inhibitory effect against cancer cells. The results of colony formation test also outlined that the GO-DOX also exerted a higher inhibitory effect on these cells.

Noticeably, the spheroids formation was decreased following the treatment with GO-DOX compared to the control group with a lower decrease in their number in BT-474 cells compared to MCF-7; highlighting that the GO-DOX treatment was more effective against the MCF-7 cells.

Furthermore, the results of cell migration and invasion by counting the remaining cells with and without the presence of matrigel exhibited that BT474 cells had a higher percentage of invasion than MCF7cells, respectively and the BT474 cells percentage was the same in both conditions. Therefore, the both cell lines exhibited a low percentage of invasion.

\section{Declarations}

\section{Funding}

This research was funded by Islamic Azad University, Iran.

\section{Code availability}

Not applicable

\section{Conflict of interest}

The authors declare no conflict of interest.

\section{Authors' contributions}

Mehdi Pooladi and, Maryam Teimouri designed the study, dathcred and analyzed the data and wrote the paper. Mahsa Ebrahimi, and Mehdi Pooladi contributed to study desigh.

\section{References}

1. Bertram, J. S. (2000). The molecular biology of cancer. Molecular aspects of medicine, 21(6), 167223.

2. Vineis, P., \& Wild, C. P. (2014). Global cancer patterns: causes and prevention. The Lancet, 383(9916), 549-557. 
3. Ehsanfar, P., Teimouri, M., \& Pooladi, M. (2020). Investigating Characterizations and Antifungal Effects of Solid Lipid Nanoparticles (SLNs) Loaded with Essential Oil of Citrus Aurantifolia on Isolated Malassezia Strains. Archives of Advances in Biosciences, 11(3), 43-55.

4. Telli, M. L., Gradishar, W. J., \& Ward, J. H. (2019). NCCN Guidelines Updates: Breast Cancer. Journal of the National Comprehensive Cancer Network, 17(5.5), 552-555.

5. Teimouri, M., \& Pooladi, M. (2021). Anti-Angiogenic and Anti-Proliferative Effects of Physalis Alkekengi Hydroalcholic Extract on Breast Cancer in Mice. Journal of Fasa University of Medical Sciences, 10(4), 1-8.

6. Howell, A., Cuzick, J., Baum, M., Buzdar, A., Dowsett, M., Forbes, J. F., Hoctin-Boes, G., Houghton, J., Locker, G. Y., \& Tobias, J. S. (2005). Results of the ATAC (Arimidex, Tamoxifen, Alone or in Combination) trial after completion of 5 years' adjuvant treatment for breast cancer. Lancet, 365(9453), 60-62.

7. Navya, P. N., Kaphle, A., Srinivas, S. P., Bhargava, S. K., Rotello, V. M., \& Daima, H. K. (2019). Current trends and challenges in cancer management and therapy using designer nanomaterials. Nano convergence, 6(1), 23.

8. Lim, E. K., Kim, T., Paik, S., Haam, S., Huh, Y. M., \& Lee, K. (2015). Nanomaterials for theranostics: recent advances and future challenges. Chemical reviews, 115(1), 327-394.

9. Duran, N., Martinez, S. T. P., Silveira, C., Duran, M., de Moraes, C. M., Simoes, A. B., Alves, M. L., O. J., \& Favaro, W. (2015). Graphene oxide: a carrier for pharmaceuticals and a scaffold for cell interactions. Current topics in medicinal chemistry, 15(4), 309-327.

10. Jiang, J. H., Pi, J., Jin, H., Cai, \& J. Y (2018). Functional graphene oxide as cancer-targeted drug delivery system to selectively induce oesophageal cancer cell apoptosis. Artificial cells nanomedicine, and biotechnology, 46(sup3), S297-\$307.

11. Qin, X. C., Guo, Z. Y., Liu, Z. M., Zhang, W., Wan, M. M., \& Yang, B. W. (2013). Folic acid-conjugated graphene oxide for cancer targeted chemo-photothermal therapy. Journal of photochemistry and photobiology B: Biology, 120, 156-162.

12. Kumar, S., Srivastava, S., Yadav, B. K., Lee, S. H., Sharma, J. G., Doval, D. C., \& Malhotra, B. D. (2015). Reduced graphene oxide modified smart conducting paper for cancer biosensor. Biosensors and Bioelectronics, 73, 114-122.

13. Zhang, L. N., Deng, H. H., Lin, F. L., Xu, X. W., Weng, S. H., Liu, A. L., Lin, X. H., Xia, X. H., \& Chen, W. (2014). In situ growth of porous platinum nanoparticles on graphene oxide for colorimetric detection of cancer cells. Analytical chemistry, 86(5), 2711-2718.

14. Wang, F., Sun, Q., Feng, B., Xu, Z., Zhang, J., Xu, J., Lu, L., Yu, H., Wang, M., Li, Y., \& Zhang, W. (2016). Polydopamine-Functionalized Graphene Oxide Loaded with Gold Nanostars and Doxorubicin for Combined Photothermal and Chemotherapy of Metastatic Breast Cancer. Advanced healthcare materials, 5(17), 2227-2236.

15. Yang, D., Feng, L., Dougherty, C. A., Luker, K. E., Chen, D., Cauble, M. A., Holl, M. M., Luker, G. D., Ross, B. D., Liu, Z., \& Hong, H. (2016). In vivo targeting of metastatic breast cancer via tumor vasculature- 
specific nano-graphene oxide. Biomaterials, 104, 361-371.

16. Muzyka, R., Kwoka, M., Smędowski, Ł, Díez, N., \& Gryglewicz, G. (2017). Oxidation of graphite by different modified Hummers methods. New Carbon Materials, 32(1), 15-20.

17. Jiang, G., Lin, Z., Chen, C., Zhu, L., Chang, Q., Wang, N., \& Tang, H. (2011). TiO2 nanoparticles assembled on graphene oxide nanosheets with high photocatalytic activity for removal of pollutants. Carbon, 49(8), 2693-2701.

18. Teng, C. Y., Yeh, T. F., Lin, K. I., Chen, S. J., Yoshimura, M., \& Teng, H. (2015). Synthesis of graphene oxide dots for excitation-wavelength independent photoluminescence at high quantum yields. Journal of Materials Chemistry C, 3(17), 4553-4562.

19. Teng, C. Y., Nguyen, B. S., Yeh, T. F., Lee, Y. L., Chen, S. J., \& Teng, H. (2017). Roles of nitrogen functionalities in enhancing the excitation-independent green-color photoluminescence of graphene oxide dots. Nanoscale, 9(24), 8256-8265.

20. Fiorillo, M., Verre, A. F., lliut, M., Peiris-Pagés, M., Ozsvari, B., Gandara, R., Cappello, A. R., Sotgia, F., Vijayaraghavan, A., \& Lisanti, M. P. (2015). Graphene oxide selectively targets cancer stem cells, across multiple tumor types: implications for non-toxic cancer treatment, via "differentiation-based nano-therapy". Oncotarget, 6(6), 3553.

21. Yoon, H. J., Kim, T. H., Zhang, Z., Azizi, E., Pham, T. M., Paoletti, C., Lin, J., Ramnath, N., Wicha, M. S., Hayes, D. F., \& Simeone, D. M. (2013). Sensitive capture of circulating tumour cells by functionalized graphene oxide nanosheets. Nature nanotechnology, 8(10), 735-741.

22. Kim, H. W., Yoon, H. W., Yoon, S. M., Yoo, B. M., Ahn, B. K., Cho, Y. H., Shin, H. J., Yang, H., Paik, U., Kwon, S., \& Choi, J. Y. (2013). Selective gas transport through few-layered graphene and graphene oxide membranes. Science, 342(6154), 91-95.

23. Yang, K., Wan, J., Zhang, S., Tian, B., Zhang, Y., \& Liu, Z. (2012). The influence of surface chemistry and size of nanoscale graphene oxide on photothermal therapy of cancer using ultra-low laser power. Biomaterials, 33(7), 2206-2214.

24. Ku, S. H., \& Park, C. B. (2013). Myoblast differentiation on graphene oxide. Biomaterials, 34(8), 20172023.

25. Alibolandi, M., Mohammadi, M., Taghdisi, S. M., Ramezani, M., \& Abnous, K. (2017). Fabrication of aptamer decorated dextran coated nano-graphene oxide for targeted drug delivery. Carbohydrate polymers, 155, 218-229.

26. Sasidharan, A., Swaroop, S., Chandran, P., Nair, S., \& Koyakutty, M. (2016). Cellular and molecular mechanistic insight into the DNA-damaging potential of few-layer graphene in human primary endothelial cells. Nanomedicine: Nanotechnology Biology and Medicine, 12(5), 1347-1355.

27. Chatterjee, N., Eom, H. J., \& Choi, J. (2014). A systems toxicology approach to the surface functionality control of graphene-cell interactions. Biomaterials, 35(4), 1109-11027.

28. Yuan, Y., Gao, X., Wei, Y., Wang, X., Wang, J., Zhang, Y., \& Gao, C. (2017). Enhanced desalination performance of carboxyl functionalized graphene oxide nanofiltration membranes. Desalination, 405, 29-39. 
29. Dutta, T., Sarkar, R., Pakhira, B., Ghosh, S., Sarkar, R., Barui, A., \& Sarkar, S. (2015). ROS generation by reduced graphene oxide ( $\mathrm{rGO}$ ) induced by visible light showing antibacterial activity: comparison with graphene oxide (GO). RSC advances, 5(98), 80192-80195.

30. Ordikhani, F., Farani, M. R., Dehghani, M., Tamjid, E., \& Simchi, A. (2015). Physicochemical and biological properties of electrodeposited graphene oxide/chitosan films with drug-eluting capacity. Carbon, 84, 91-102.

31. Chen, J., Wang, X., \& Han, H. (2013). A new function of graphene oxide emerges: inactivating phytopathogenic bacterium Xanthomonas oryzae pv. Oryzae. Journal of nanoparticle research, 15(5), 1-4.

32. Chang, Y., Yang, S. T., Liu, J. H., Dong, E., Wang, Y., Cao, A., Liu, Y., \& Wang, H. (2011). In vitro toxicity evaluation of graphene oxide on A549 cells. Toxicology letters, 200(3), 201-210.

33. Arya, N., Arora, A., Vasu, K. S., Sood, A. K., \& Katti, D. S. (2013). Combination of single walled carbon nanotubes/graphene oxide with paclitaxel: a reactive oxygen species mediated synergism for treatment of lung cancer. Nanoscale, 5(7), 2818-2829.

34. Hu, X., Ouyang, S., Mu, L., An, J., \& Zhou, Q. (2015). Effects of graphene oxide and oxidized carbon nanotubes on the cellular division, microstructure, uptake, oxidative stress, and metabolic profiles. Environmental Science \& Technology, 49(18), 10825-10833.

35. Vallabani, N. V., Mittal, S., Shukla, R. K., Pandey, A. K., Dhakate, S. R., Pasricha, R., \& Dhawan, A. (2011). Toxicity of graphene in normal human lung cells (BEAS-2B). Journal Of Biomedical Nanotechnology, 7(1), 106-107.

36. Chung, C., Kim, Y. K., Shin, D., Ryoo, S. R., Hong, B. H., \& Min, D. H. (2013). Biomedical applications of graphene and graphene oxide. Accounts of chemical research, 46(10), 2211-2224.

37. Tadyszak, K., Wychowaniec, J. K., \& Litowczenko, J. (2018). Biomedical applications of graphenebased structures. Nanomaterials, 8(11), 944.

\section{Figures}




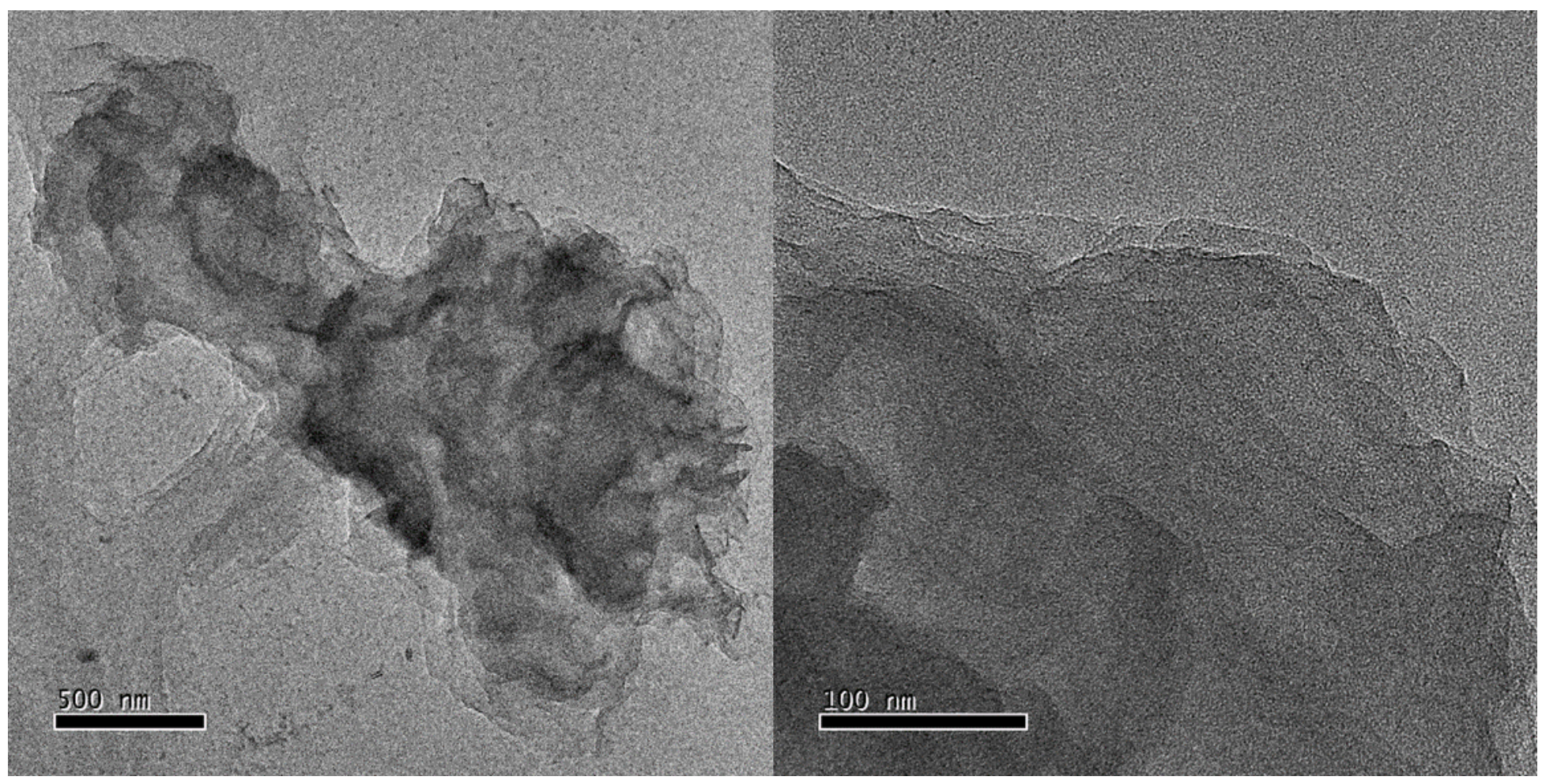

\section{Figure 1}

transmission lectron microscopy (TEM) image of synthesized GO 

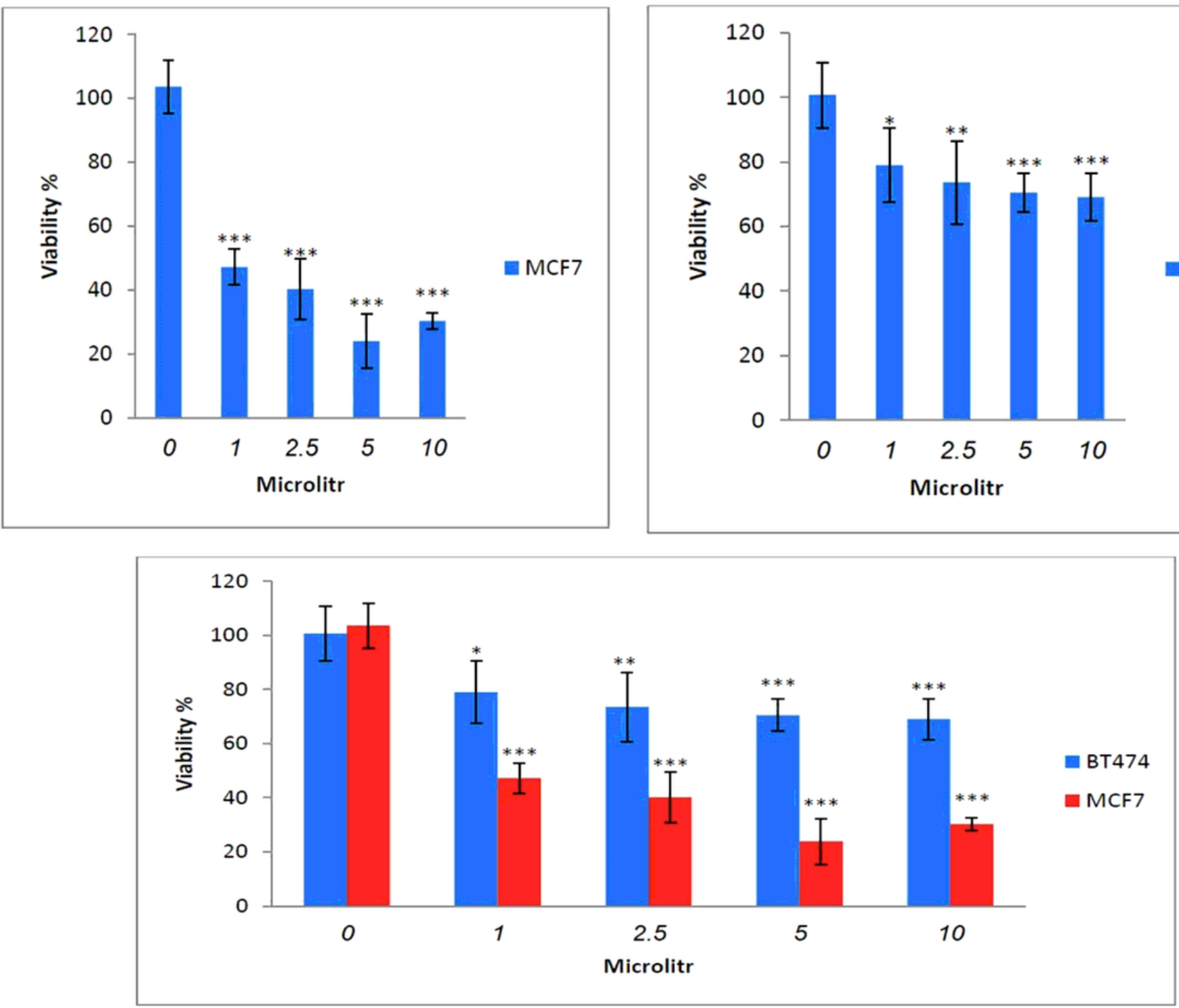

Figure 2

Charts A and B in the MTT test depict the different concentrations of GO-DOX on the MCF7 and BT474 breast cancer cell lines. The stock concentration of GO-DOX was $10 \mathrm{mg} / \mathrm{mL}$. Figure $\mathrm{C}$ exhibits a comparison of the survival rates of MCF7 and BT474 cell lines using the GO-DOX. There was a significant difference between each group and the control group * indicates significance at the level of $p<0.05$, ** shows significance at the $p<0.01$ level and $* \star \star$ indicates the significance at the $p<0.001$ level. 


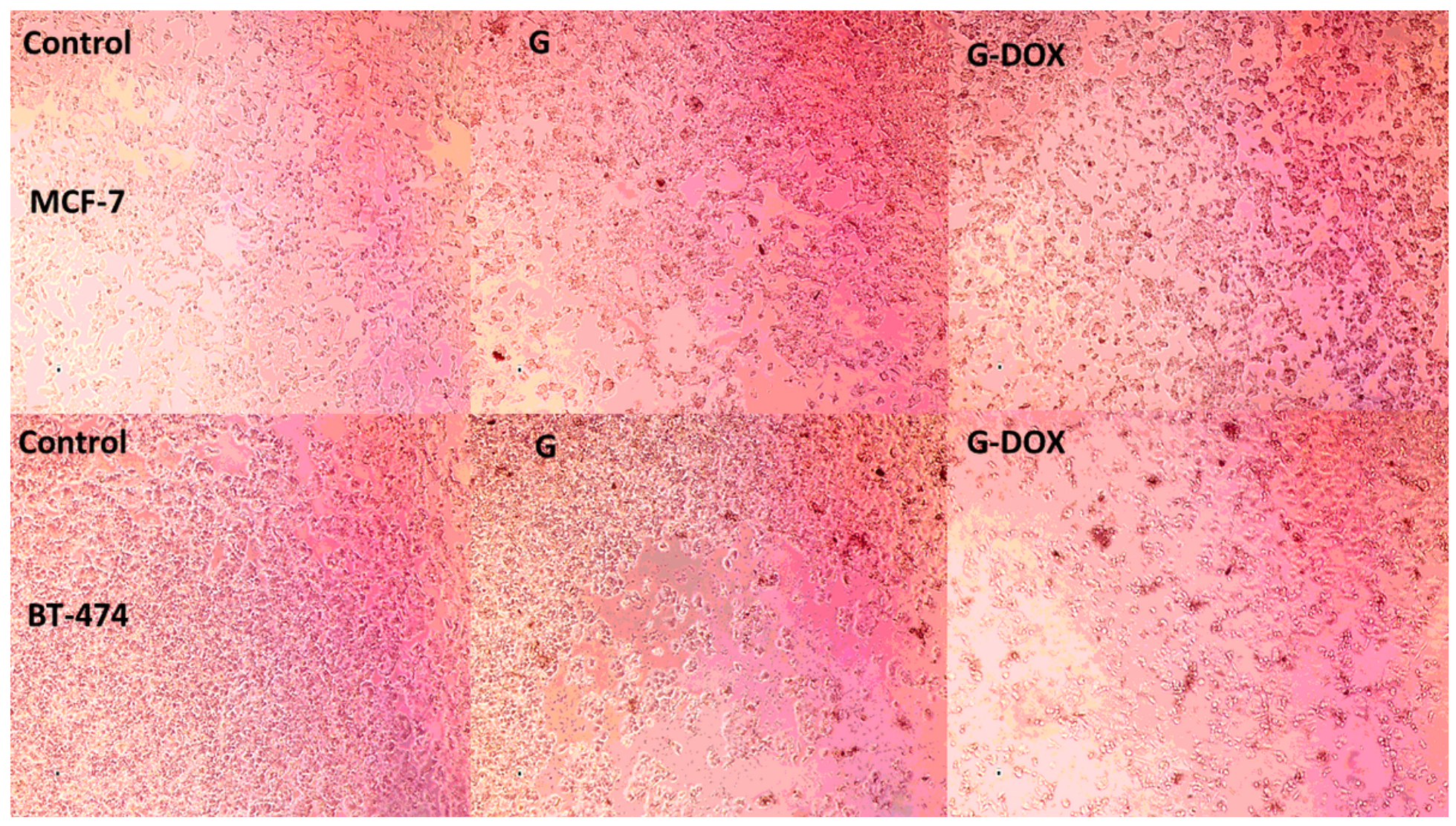

\section{Figure 3}

MCF7 and BT474 cancer cell lines following the effect of drug groups under light microscopy; the groups included control, GO and GO-DOX. 


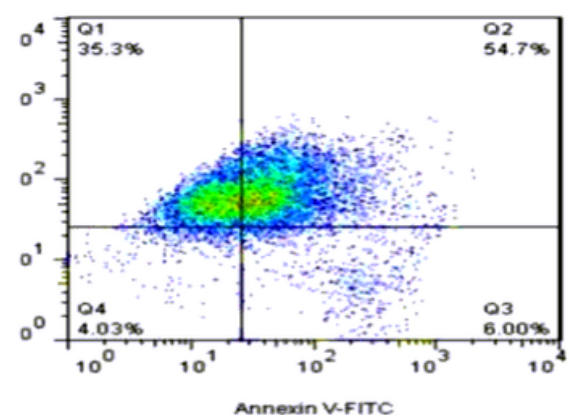

MCF7 Test-T.056 FSC.H. SSC-H subset 10460

MMCF7 Treat

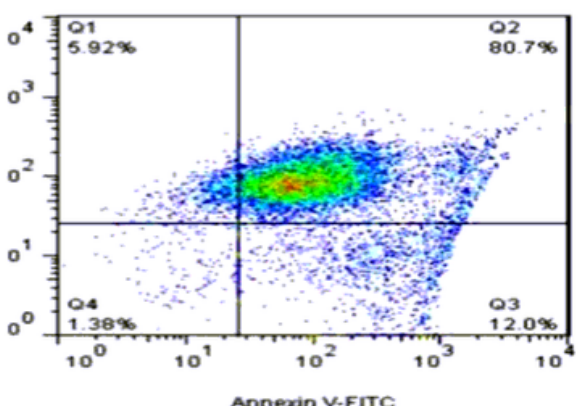

BT. Treat-T.058
FSC-H, SSC-H subset
9867 9867

BT474 Treat

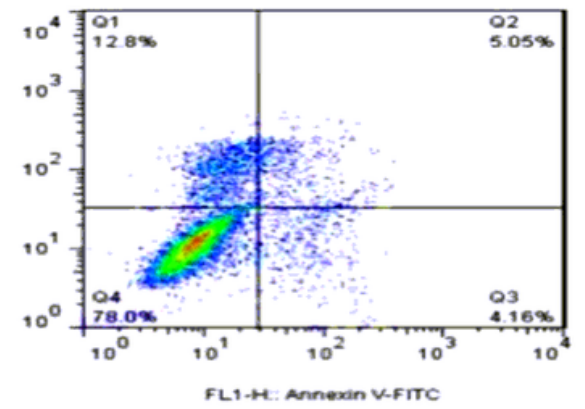

mer7-Dou-T 037 MCrT-Dou.T. 037
FSC-H, SSC-H subset 8698

\section{MCF7 - DOX}

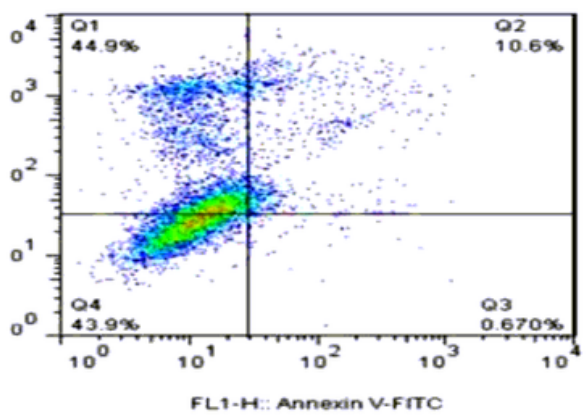

BT-Con-T.039 FSC-H, SSC-H subset 7017

BT 474 -DOX

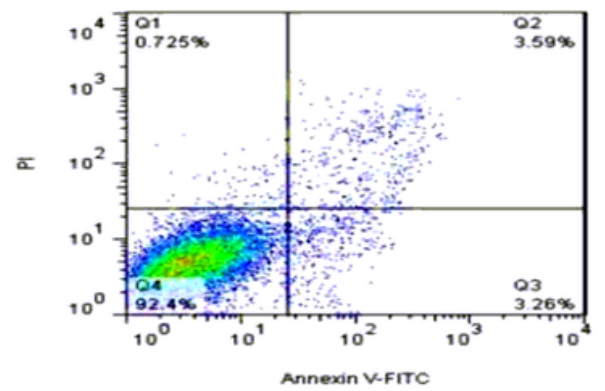

MCF 7 Control - T.055 FSC-H, SSC-H subset

MCF7 Control

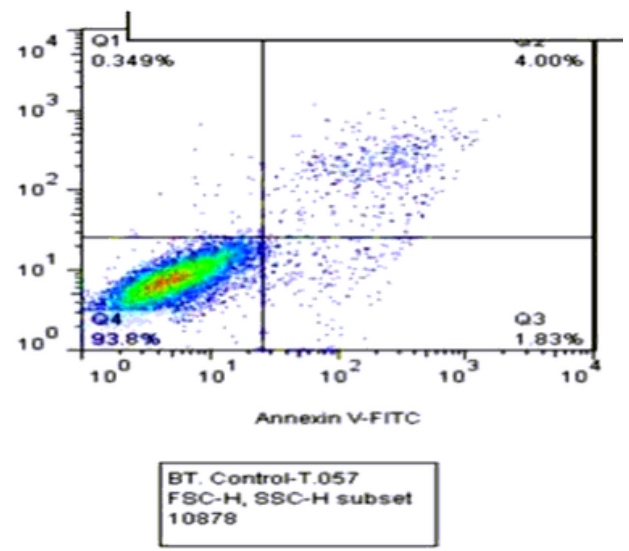

BT474 Control

Figure 4

Rate of apoptosis in MCF7 and BT474 cell line 

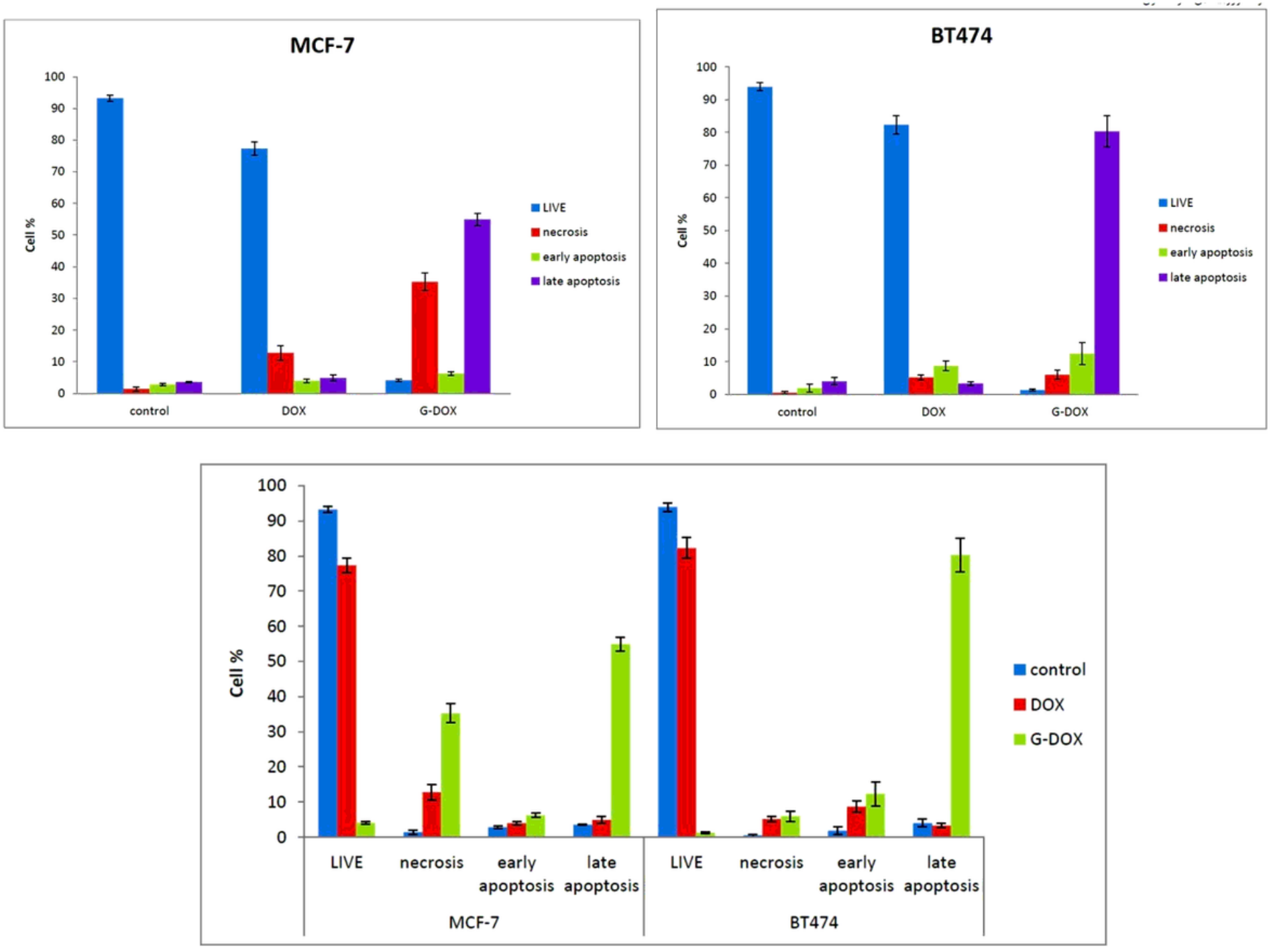

Figure 5

Graph of the apoptosis in MCF7 and BT474 cell lines treated with DOX, GO, GO-DOX and control 


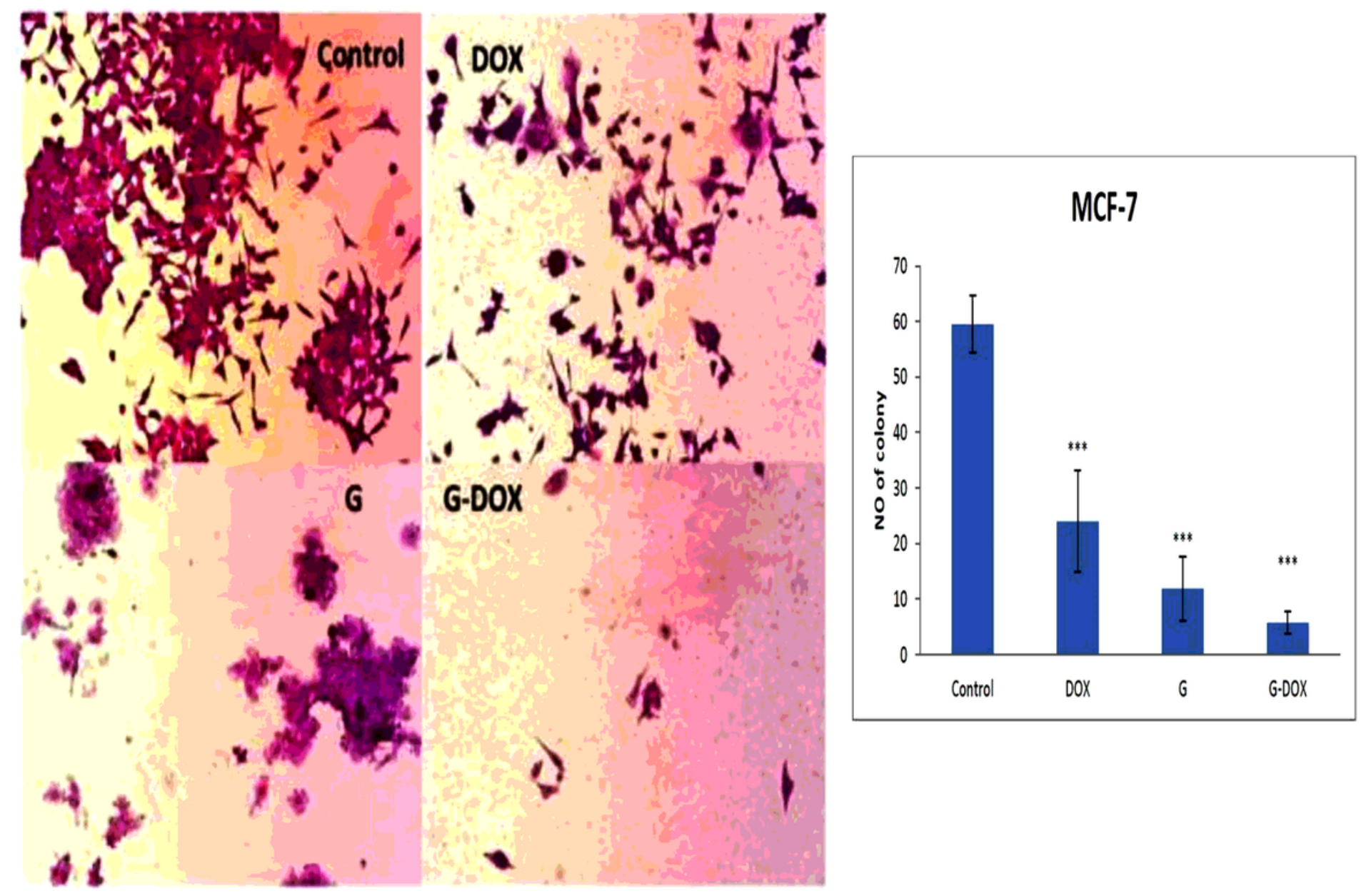

Figure 6

Colony formation in MCF7, DOX, GO, GO-DOX cells and control groups 

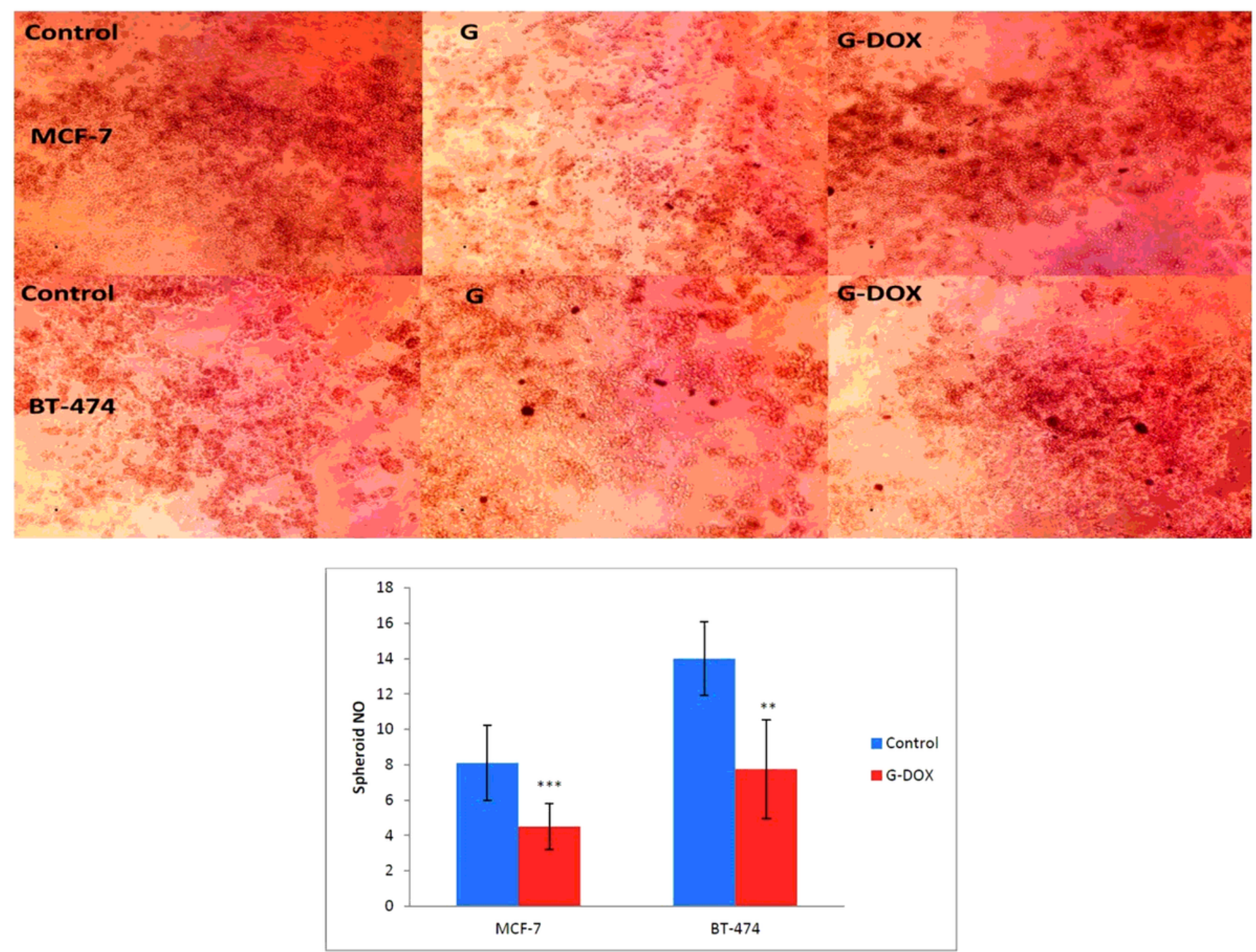

Figure 7

Microscopic images of MCF7 and BT474 cell spheres on an agar substrate in the control, GO and GODOX groups. Images of the GO-DOX treatment group exposed to GO (24 hours, in the middle figure), and a GO-DOX have been represented. The image of the control group was taken simultaneously with GO-DOX. 


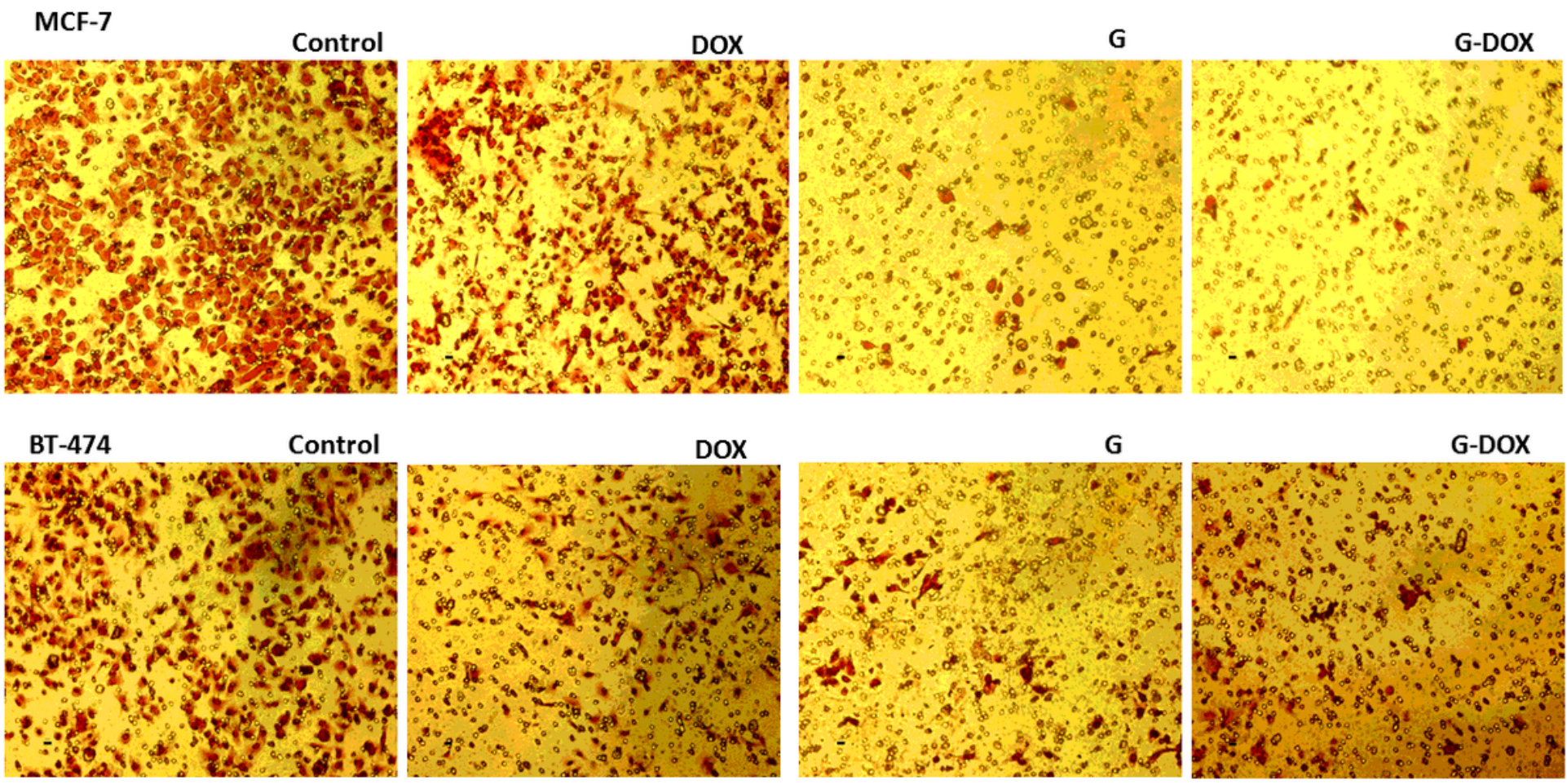

\section{Figure 8}

Light microscope images of transvel plates containing MCF-7 and BT-474 cells on matrigel and without matrigel to evaluate cell invasion 

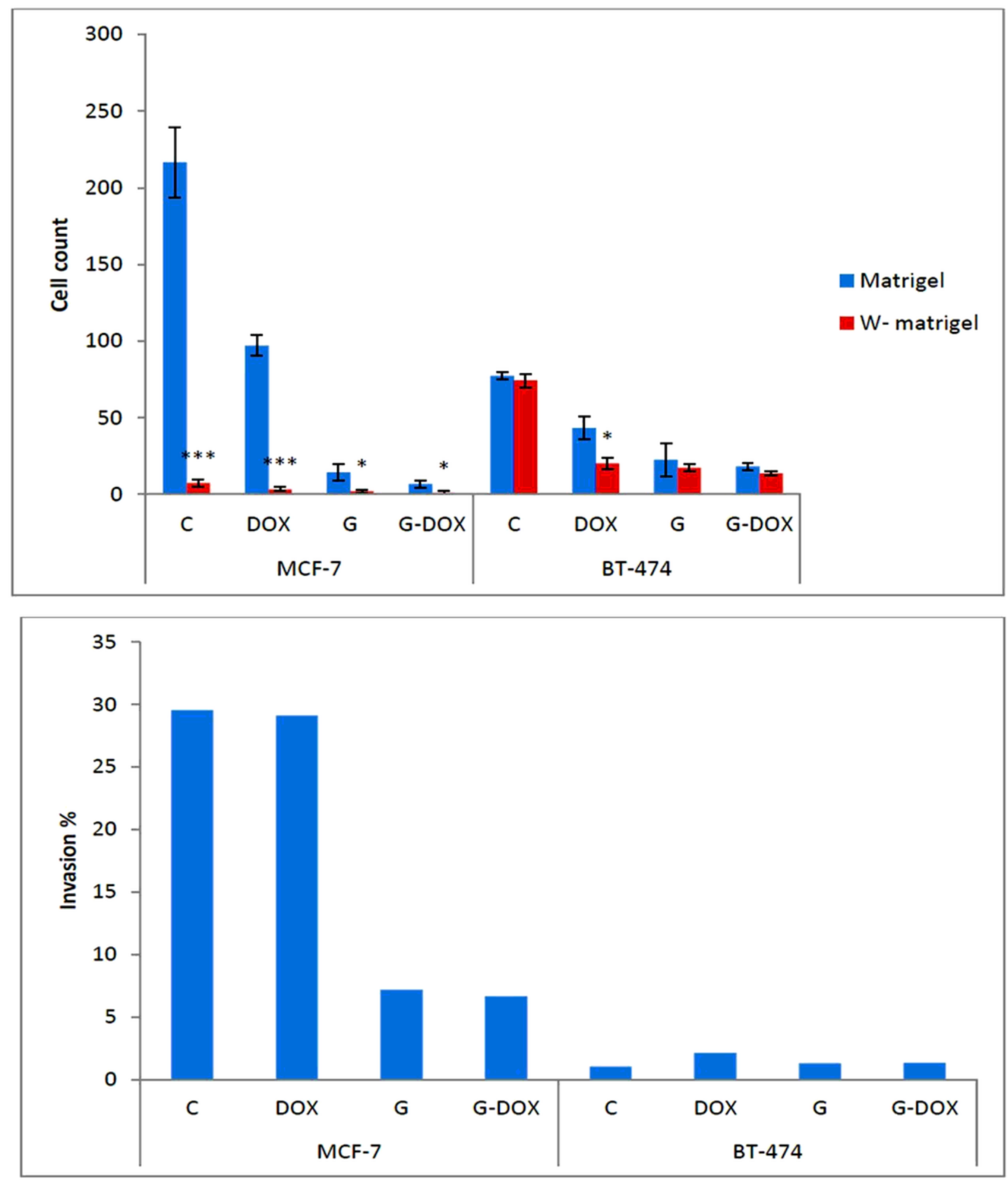

\section{Figure 9}

Cell invasion and migration chart of MCF-7 and BT-474 cells under the influence of DOX, GO and GO-DOX. The cells counted on the transvel plate in the presence of matrigel represent invasive cells, and the cells counted on the transvel plate without matrigel represented migrating cells which was a significant difference regarding the presence and absence of the matrigel. Diagram of cell invasion percentage of 
the studied cells was calculated by dividing the number of cells counted on the plate containing matrigel by the number of cells counted on the transvel plate without matrigel.

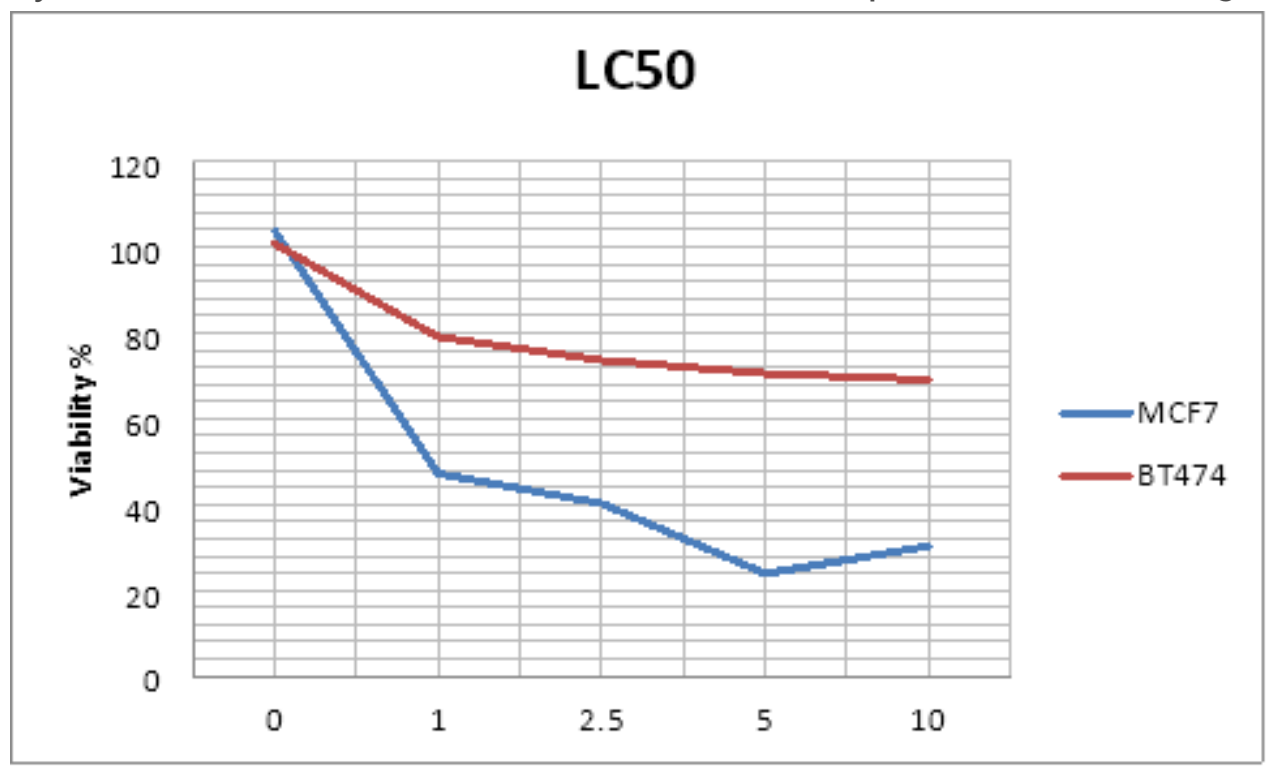

Figure 10

Chart 1. LC50 revealed the effect of GO-DOX on MCF7 and BT474 cancer cell lines. 